\title{
Self-reported diseases and the risk of non-vertebral fractures: the Tromso study
}

\author{
L. A. Ahmed • H. Schirmer • G. K. Berntsen • \\ V. Fønnebø $\cdot$ R. M. Joakimsen
}

Published online: 6 February 2009

(C) International Osteoporosis Foundation and National Osteoporosis Foundation 2009

\section{Erratum to: Osteoporos Int (2006) 17: 46-53 \\ DOI 10.1007/s00198-005-1892-6}

Owing to a technical error, a number of non-vertebral fractures were not included in the database.

Owing to changes in the informed consents for some of the participants, at the time of repeated analyses, the study cohort changed from 27,159 to 26,905 participants.

A total of 758 men and 1124 women (not 446 men and 803 women as stated in the publication) suffered at least one nonvertebral fracture during the follow-up period.

The independent associations between fractures and some of the self-reported diseases in men and women slightly changed at some but not all fracture locations. In addition, men with self-reported stroke and psychiatric disorders suffered an increased risk of wrist fracture $[R R$
4.1 (95\% CI 1.8-9.1)] and hip fracture [RR 2.1 (95\% CI 1.1-4.0)], respectively. Women with self-reported diabetes and stroke suffered the same increased risk of hip fracture [RR 1.7 (95\% CI 1.0-2.9)]. Moreover, women with self-reported stroke and epilepsy suffered an increased risk of all non-vertebral fractures [RR 1.4 $(95 \%$ CI $1.1-2.0)$ ] and [RR 1.6 (95\% CI $1.0-2.5)$, respectively.

Nevertheless, the conclusion was unaffected as the independent non-vertebral fracture risk associated with self-reported chronic diseases differed between men and women as well as among fracture sites in the same gender, and increasing burden of disease increased fracture risk in both men and women.

We apologize for any inconvenience caused by this unfortunate error.

The online version of the original article can be found at http://dx.doi. org/10.1007/s00198-005-1892-6.

L. A. Ahmed $(\bowtie) \cdot H$. Schirmer · G. K. Berntsen · V. Fønnebø Institute of Community Medicine, University of Tromsø, 9037 Tromsø, Norway

e-mail: Luai.Awad@ism.uit.no

H. Schirmer

Department of Cardiology, University Hospital of Tromsø,

Tromsø, Norway

R. M. Joakimsen

Department of Internal Medicine, University Hospital of Tromsø,

Tromsø, Norway 